\title{
印尼侨生马来由文学之谈 \\ A GLIMPSE OF CHINESE-MALAY LITERATURE
}

\author{
Cendrawaty Tjong
}

Chinese Department, Bina Nusantara University, Jl. Kemanggisan Ilir III No. 45,

Kemanggisan/Palmerah, Jakarta Barat 11480, CTjong@binus.edu

\begin{abstract}
Chinese-Malay literature begans in the end of $19^{\text {th }}$ century. The beginning of this period was known from the works depicted Classical-Malay literature. In the development, due to the booming of publication houses and newspaper agencies, this school of literature flourished. The origin of this period was closely related to Chinese-descendants, background and history. The long history, the big numbers of works and the miscellaneous contents of the works were the characteristics of this period. Chinese-Malay literature period was the period highlighted with typical Chinese-Indonesian society.
\end{abstract}

Keywords: Indonesia, Chinese-descendants, literature

\section{内容提要}

印尼侨生马来由文学产生于 19 世纪末, 最初以中国古典小说的翻译和仿效马来古典文学为 初期作品。后来出版社、印刷公司与报社的大量出现推动了文学的发展。它的产生与华侨社会 的历史背景联在一起。历史悠久、作品数量庞大、内容丰富多样化是它的主要的特点。印尼侨 生马来由文学阶段是个富有印尼华侨社会显著特点的文学阶段。

关键词: 印尼, 侨生, 文学 
前言

印尼是个岛屿国家, 由 17000 多个岛屿组成, 有着历史悠久和多元文化。印尼也住着各种 各样的民族, 如: 爪哇族、巽达族、马杜拉族、华族等。在这种有着多元文化和多种民族的环 境下, 华人创作出来的文学作品极具印尼地方特色, 这些华人创作出来的文学作品就是所谓的 印尼华人文学。

\section{印尼侨生马来由文学使用通俗马来由语}

印尼华人文学可以分成三种: 印尼侨生马来由文学、印尼华人印尼文文学和印尼华人文学, 其中印尼侨生马来由文学的历史较长、作品也很多。印尼侨生马来由文学产生于 19 世纪末到 20 世纪 60 年代。19 世纪印尼还处在荷兰殖民统治时期, 当时荷兰官方之间使用荷兰语来进行 交流; 印尼贵族阶层都接受了荷兰的教育, 他们之间使用荷兰语和贵族的马来语交流, 这种贵 族马来语后来被殖民地政府强制规定成为印尼官方正式语言; 而当时的印尼侨生与侨生之间却 使用华人马来由语。这种语言不同于贵族马来由语, 除了含有当时侨生之间交流使用的惯用语 以外, 还含有许多福建方言、爪哇语、荷兰语。由于这种华人马来由语被社会上的各个阶层广 泛使用, 后来它被称为通俗马来由语 (Melayu Rendah) 或者巴刹马来由语(Melayu Pasar)。通俗 马来由语影响深远, 它不仅在生活上、工作上被广泛运用, 而且也被作家用于他们的文学创作 和作品翻译中, 因此他们创作的文学作品可以被社会上的各个阶层和各个民族接受。印尼侨生 马来由文学作品就是指这些印尼侨生使用通俗马来由语进行创作或翻译的文学作品。

\section{印尼侨生马来由文学的特点}

印尼侨生马来由文学主要包括以下几个的特点:

\section{一、历史悠久}

要了解此特点, 我们就要先了解印尼侨生在印尼居住的历史背景以及马来由文学产生的历 史背景。

据记载, 华人大约 10 世纪已经定居在印尼。这是根据来自 10 世纪一位阿拉伯游厉家马素提 ( $\mathrm{Al}$ Mas'oudi）撰述的《黄金牧地》 (Les Prairus d'or《金草原》) 记载了马素提本人游历非洲、南亚、 东南亚、中国时, 在 943 年途径印尼苏门答腊东南部沿海地区时, 发现那里有很多中国人从事 耕种, 尤其是在巨港一带, 中国人最集中。他们都是唐末黄巢起义军攻广州城之后, 难逃至印 尼苏门答腊岛。西方学者莱佛士著《爪哇史》和坎贝尔著《爪哇的过去和现在》也记载了 10 世 纪上半叶有一艘中国海船在爪哇三宝垄附近的海上沉没, 船员和乘客都分别在扎巴拉、三宝垄、 直葛上岸, 其管仓者向直葛土王献上宝石之后, 获得土王的许可, 定居在此地 (李学民、黄昆 章, 2005:19 页)。后来, 印尼受到荷兰殖民地的强烈统治, 统治了 350 年。荷兰殖民时期, 有一 批人通过 “卖猪仔”契约被荷兰建立的东印公司安排在印尼邦加岛开矿, 在这样的背景下形成了 华人社会。

清末由于中国国内政治动荡, 所以有一大批华人南移印尼。早期的印尼人, 乘着唐代末年 黄巢动乱就南移印尼。他们为了寻找安定的生活而来印尼, 也有被卖成奴隶, 乘船来印尼。这 些人大部分都是男生, 一般来说, 他们携带家眷同来, 到了印尼, 他们只好随乡入俗, 与非回 教徒或者名义上的回教徒的当地女人结婚, 然后定居下来。这些华人及他们的后裔, 后来组成 
了相当稳定的和统一的社会，俗称土生华人社会。民族于民族之间培养了友善的生活环境。19 世纪前半叶, 这社会渐趋自立, 因为其间的男女比率逐渐平衡, 减少了与当地女人的通婚。

19 世纪初, 南来印尼的华人数量很多, 因此跟当地出生的印尼华人形成了新客和土生华人 之分。这些新客通常都很快地融入在土生华人社会。而土生华人被称为“侨生”或“babah”，这个 词含有贬义的意思。由于侨生华人出生在印尼、生活在印尼, 除了会一点儿带闽南方言的惯用 语以外, 他们已经不会使用汉语进行交流或创作了, 因此他们的作品都是使用通俗马来由语来 编写的。

到了 20 世纪初随着华侨生活越来越稳定、经济水平越来越上升, 越来越多印尼侨生从事新 闻记者和经商, 并出现了大量的出版社和印刷公司, 这些都给印尼侨生创作带来了很大的影响。 这些记者把他们日常看在眼里的事物都通过写作表达出来; 从事经商的侨生作者把经商所面临 的等问题写进作品里，使他们创作的作品富有社会生活的现实特征。

最初出现的土生华人文学作品, 是中国古典小说的翻译和仿效马来古典文学的作品。例如, 1882 年出版的《海瑞》罢官的故事，1883 年出版的《三国演义》，1885 年出版的《山伯英台》 以及 1884 年问世的《西蒂·阿克巴丽的故事》都是这个时期的产物。根据文学评论家普拉穆迪 亚.阿南达.杜尔, 印尼侨生马来由文学是印尼现代文学的先驱。早在印尼文学出生之前, 社会上 已经大量流传印尼侨生马来由文学, 如: 以上的翻译作品以及 19 世纪末编写的侨生马来由作品 都比印尼文学史上第一部小说《那个嘉明和那个约汉》（Azab dan Sengsara）写得还要早。

印尼侨生马来由文学始于 19 世纪末。据 1985 年苏尔梦写的《Literature in Malay by Chinese of Indonesia》印尼侨生作家最早编写的侨生马来由文学作品《泰国国王来巴达维的诗词》写于 1871 年 5 月; 但关于印尼土生马来由文学到底什么时候结束, 这没有具体的划分。梁友兰认为 印尼侨生马来由文学 1962 年已经结束了 (Nio Joe Lan, 1962)。从政策来看, 1962 年后印尼华侨 面对国籍问题, 印尼政府规定印尼华侨必须选择他们的国籍, 当时很多印尼华侨加入了印尼国 籍, 因此 1962 年后已经没有印尼侨生马来由文学的说法了。从历史来看, 1928 年 10 月 28 日, 青年第二届代表大会在巴城召开, 会议结束后, 印尼青年通过“青年誓言”誓词, 提出了“一个民 族、一个祖国和一种语言”的口号。他们把印尼语成为国家统一运用的语言, 从此以后政府推广 规范的印尼语, 并提倡使用印尼语来进行写作。要执行这个青年誓言并不是一、两天的问题, 何况对当时的印尼侨生作家, 他们在生活上、写作上已经习惯了使用侨生马来由语, 因此不能 即将改变，直到 1965 年以后再也没有出现利用侨生马来由语写出来的作品。

\section{二、印尼侨生马来由文学数量庞大}

印尼侨生马来由语文学的数量和作家很多。据研究这方面的法国女学者一一格劳汀·沙尔蒙

(Claudine Salmon) 博士：当时侨生作家和翻译家有 806 人, 作品 2757 本, 佚名作品 248 本, 作品总共统计有 3005 本; 这 3005 本中可以分为剧本 73 本, 诗歌 183 本, 译自西方的作品 233 本，译自中国的作品 759 本，长短篇小说创作 1398 本 (耶谷. 苏玛尔卓, 1998:18 页)。印尼华 人的印尼文文学作品最初是用马来语翻译中国古典文学著作为主, 如《海公小红袍全传》1882 年、《列国志》1883 年、《三国演义》1883 年、《正德皇游江南》1884 年、《今古奇观》1884 年 等作品(耶谷. 苏玛尔卓, 1998:18 页)。 
如果我们把当时流传的 3005 本侨生马来由文学作品分期，就可以把它们分成 4 个时期:

1、李金福时期（1884-1910）

这时期是以侨生马来由文学作家之一李金福而命名的。他是印尼第一个使用通俗马来由语 来翻译与改写小说和诗歌。在他之前, 社会上使用的通俗马来由语显得混乱, 没有规范化也没 有标准化。李金福把这些混乱、无规范和标准的语言整理, 使通俗马来由语规范化和标准化。 从此, 使用规范化的通俗马来由语创作的作家越来越增加。他也于 1884 年出版了印尼第一部的 语法书《Melayu Betawi》, 也写了拼音字母拼读规则《Kitab Eja A.B.C》。当时人们所使用的通俗 马来由语都以他写的语法书为标准。此外, 他也创作了诗歌和翻译了很多作品。人们为了纪念 他所做的一切，并称他为“印尼侨生马来由文学之父”。

这时期的前半期大部分是翻译西方和中国的古典小说; 而后半期开始出现了作者创作的小 说, 如: 张振文(Thio Tjin Boen)写了《黄西的故事》(Cerita Oey Se)、吴炳良(Gouw Peng Liang) 的《罗宏贵》(Lo Fen Koei)、郑登怀(The Teng Hoey)的《争夺财产》(Rebutan Harta) 等。

\section{2、发展时期（1911-1923）}

这时期西方的文学对于印尼侨生马来由文学的影响很大, 因为 1908 年荷兰殖民地政府开设 荷华学校, 招收印尼侨生。那时孙中山思想也传到印尼, 荷兰殖民地为了让侨生脱离孙中山思 想而开设这个学校, 因此这时期的作品很多是翻译英国和法国的作品、小说创造也比以前更发 展。主要的作家有张振文(Thio Tjin Boen)、吴炳良(Gouw Peng Liang)、陈振江(Tan Tjing Kang)、 陈文金(Tan Boen Kim)、赵雨水(Tio Ie Soei)和朱茂山 (Tjoe Bou San).

\section{3、小说月刊时期（1924-1945）}

这是印尼侨生马来由文学蓬勃发展时期。这时期产生了很多新作家, 如: 郭德怀 (Kwee Tek Hoay)、林庆和 (Liem King Hoo)、陈文宣 (Tan Boen Soan)、包求安 (Touw Kioe An)、陈丰文(Tan Hong Boen)、王秉禄 (Ong Ping Lok)等。其中, 郭德怀是这时期最有代表性的作家, 也是一名 记者和哲学家。除了写过很多文学作品、带有政治和宗教信仰的作品, 也编写过剧本。主要的 作品有: 《假冒的上帝》(Allah Yang Palsu)、《柏芬迪古尔的悲剧》 (Drama di Boven Digul)、《来 自克拉克陶的悲剧》(Drama dari Krakatau)、《来自芝根邦的玫瑰花》(Bunga Roos Dari Cikembang)、 《看元宵节》(Nonton Capgome)、《无灯的脚踏车》(Zonder Lentera)、《我梦中的学馆》(Ruma Sekola Yang Saya Impiken)、《华人起义的来源》(Atsal Mulahnya Timbul Pergerakan Tionghoa)等.

\section{4、结尾时期（1945-1960）}

印尼独立以后, 很多侨生作家推出文坛。这时期虽然还有出现侨生马来由文学的作品, 但 是数量渐渐减少。作品主要是短篇小说、翻译作品和武侠小说。这时期的作品多集中出版于《星 周刊》(Staar Weekly)、《美丽周刊》 (Tjantik)、《五彩周刊》 (Pantja Warna)等。应该注意的是, 印尼独立以后, 印尼政府面对双重国籍人民的问题, 为了解决这个问题, 印-中于 1954 年 4 月 签订了《中华人民共和国和印度尼西亚共和国关于双重国籍问题的条约》，取消双重国籍政策， 华侨必须选择一种国籍; 再说, 印尼独立以后也正式把印尼语当作官方语言, 从此再也没有“印 尼侨生”或“印尼侨生马来由文学”的说法了。梁友兰在 1962 年出版的《印尼华人文学》写出: “印 尼侨生马来由文学已经不存在了。根据印尼法律, 那时已经没有 “印尼侨生”的说法, 只有“印尼 籍’或‘中国籍’说法。” 


\section{三、印尼侨生马来由文学内容丰富}

印尼侨生马来由文学的除了历史悠久、作品数量庞大、内容也丰富多彩, 深受欢迎那时候 的人们热烈欢迎。文学题材产生于生活。它主要包含以下几个方面:

\section{1. 反映现实生活}

文学作品采取当时社会媒体上的大案件。印尼侨生马来由文学作家很多都是记者, 所以作 品内容采取当时报纸上的大新闻, 作品的写法也采用记者的写法, 如: 赵雨水(Tio Ie Soei)的《一 位华人拳头的生平》 (Riwayatnya Satu Bokser Tionghoa -- Tan Sie Tiat)、郭德怀 (Kwee Tek Hoay) 的《华人起义的来源》(Atsal Mulahnya Timbul Pergerakan Tionghoa)、郭德怀 (Kwee Tek Hoay) 的《来自克拉克陶的悲剧》(Drama dari Krakatau)采取 1883 年克拉克陶火山爆发的事件、郭德怀 (Kwee Tek Hoay) 《柏芬迪古尔的悲剧》 (Drama di Boven Digul)采取 1926 年的印尼共产党起义 当作作品背景等等。

除此之外，作品很多反映当时社会普遍的“小妾”（nyai）问题。印尼“小妾”的称呼是比较特 殊。Nieuwenhuys 指明“Nyai (小妾)”的称呼是 1826 年开始使用, 开始指欧洲人的仆人。根 据 Subandio 和 T.O Ihromi, “Nyai (小妾)”是来自马来由-巴达维亚语, 开始是指欧洲人的管 家女子，后来“小妾”的称呼指那些欧洲人的原住民小妾，渐渐地，“小妾”这个称呼也指其他外 国人的原住民小妾, 如: 华人的原住民小妾。荷兰殖民地时期的原住民小妾一般都来自奴隶阶 级, 这是因为从 17 世纪中期印尼的原住民一般都成为荷兰人的奴隶, 他们服务荷兰人、帮荷兰 人管理家务等。一个荷兰人家庭平均拥有十二个仆人，但也有的荷兰人家庭拥有一百多个仆人。 原住民女子希望通过仆人这个职位可以提高她们的生活水平。外表漂亮与否、态度和语言优雅 与否是界定原住民女子可否选为小妾的标准。19 世纪由于经济的原因越来越多原住民愿意把他 们的女儿卖给荷兰人或华人地主成为他们的小妾, 可是这些小妾都没有法律地位, 可以随时被 抛弃。小妾在社会的地位非常低, 她们常常挨打、挨骂、受欺负。虽然小妾的社会地位很低, 但小妾对促进两国文化或两个民族文化的交流起了重要的作用。小妾成为两国或两民族之间的 桥梁, 通过小妾其他国家或民族的人们可以更了解当时原住民的文化、宗教信仰、语言、风俗 习惯等问题。

\section{2. 带有教育性内容}

几乎每个印尼侨生文学作品都带有教育性特征, 为了教育和提醒后代人不要再犯同样的错 误。文章一开始常先介绍文章重要人物的角色, 并写着: “我讲这些故事是为了让年轻人不要犯 同样的错误、可以避免不佳的事”, 如: 张振文(Thio Tjin Boen)的《只靠两分钱就成为富翁》

（Dengen Duwa Cent Jadi Kaya）讲述了劳动和勤奋是成功之母，只有劳动得来的财产才是真实 的。这部文学作品的年轻主人公从年幼就失去了父母。他们留给他一大笔钱。由于朋友的诱惑 染上了奢博与嫖妓的习惯, 最后失去了所有财产, 剩下了两分钱。他用那两分钱做生意, 每天 刻苦耐劳地工作, 过着省吃俭用的生活, 就这样经济情况就渐渐好起来。作者通过这位年轻人 教导我们（读者）不要好吃懒做、染上恶习惯、吃喝嫖奢, 这些不良途径会使我们葄落、不长 进、贫穷; 作者告诫我们要勤奋努力、增加知识, 才能富足、贡献于社会。作者在文章的结尾 告诉读者: 劳动的手能够把石头变成金子; 不劳动的手能够把金子变成石头, 劳动是最可靠的 财富。此外, 郭德怀也通过《无灯的脚踏车》告诉人们不要贪心。贪心是一种病, 它只能让我 们阷落、失去了自我。

有一些作品也提醒人们应该注重教育子女并告诉大家每个人都得受到平等的教育。建设国 家与教育是互相联系的, 没有受到教育的人民就是落后、落后的人民就谈不起建设国家。郭德 怀的《我梦中的学馆》(Ruma Sekola Yang Saya Impiken)讲诉了作者梦中的学馆。他批评了当时 
的学馆缺少实际性, 只注重理论。作品也提到教育的重要性, 每个人都该受到教育, 提高他们 的知识, 可是不能只重视理论, 忽略了实际生活所需要的教育, 受教育的目的就是可以在现实 生活中生存、建设国家; 郭德怀的《华人起义的来源》(Atsal Mulahnya Timbul Pergerakan Tionghoa) 讲述了中华会馆对华人的教育起了重要作用。

3. 种族交流、宗教信仰、通婚的问题

很多印尼侨生马来由文学讲诉那个时候华族与其它民族或其它国际的人们和睦相处, 他们 与爪哇族、潠达族、欧美人、阿拉伯人等关系很密切。譬如：张振文的《黄西的故事》、《素密 拉姑娘》; 郭德怀的《来自芝根邦的玫瑰花》等。

在当时的印尼社会，华侨、印尼原住民和其它国籍的人民住在一起，他们和睦共处，在这 种情况下难免不发生通婚。印尼侨生马来由作家们都很关注这些通婚问题, 尤其是华人和印尼 原住民人的通婚, 但这些婚姻大部分都是悲剧的, 如: 郭德怀 1927 年写的《来自芝根邦的玫瑰 花》、Soe Lie Piet 1929 年写的《Ular yang Cantik 译 美丽的蛇》、Chang Ming Tse（张明思） 1939 年写的《Bunga Roos Merah 译 红玫瑰》等都写着通婚的悲剧。张振文 1903 年写的《黄西的故 事》里的主人公——黄西的女儿金娘要与原住民儿子结婚, 虽然未来女婿是当地的政府人员, 但是由于这是通婚, 黄西不成全他们的婚姻, 结果女儿奔跑了, 他从此就不承认女儿的身分, 断绝父女关系，后来女儿因伤心过度就去世了。

通婚波浪很大、除了受到华人父母和印尼原住民父母的反对还有宗教的问题。张振文的《黄 西的故事》里有注: “Anak perempuan bangsa Cina tida tau keluar pintu, lagi Oey Se itu orang kaya besar, kendati orang itu berpangkat regent, tida nanti Oey Se mau buat mantu, sebab lain bangsa, kalu sampe ada juga orang perampuan Cina bersuami pada lelaki dari lain bangsa, harus dikatakan orang itu sudah tiada hargakan dirinya sendiri dan tiada harus dicampuri orang baik baik sebab melanggar aturan hukum adab” (A.S. dan Benedanto, 2000). (华侨的女子不能出门。再说黄西是个富翁, 虽然 要娶他女儿的男子是县长, 是社会有权利的人, 但是黄西还是不想把他成为他的女婿。如果有 个华侨跟一个外族的男子通婚, 应该说那个人已经没有自尊了, 别人也不可以与她来往, 因为 她犯了礼节)。

张振文在《Cerita Nyai Soemirah 译小妾素密拉的故事》里 写着印尼原住民母亲对她女 儿要嫁给华族男子的对话 :

母亲: “Apa namanya kalu satu gadis Bumiputera musti jadi gundiknya seorang Cina ?”

（一个原住民女子怎么可以成为华人的小妾呢? )

素密拉: “Gundik kalu dipiara saja, tetapi kalu dinikahken...”

（小妾一般是被男人养的，但如果能结婚呢？)

母亲: “Di mesjid ?” (A.S. dan Benedanto, 2001).

(在清真寺? )

母亲: “Angkau pikir tida ada halangannya satu perampuan Bumiputera jadi bininya seorang kafir?” （你认为一个原住民女子可以成为一个无信仰人的妻子吗? )

素密拉: “Maaf, ibu, saya kepingin tau ibu punya pemandangan begimana dengen itu nama kafir ?” （对不起，母亲，我想知道您认为的无信仰是什么？）

母亲: “Orang yag tida Islam itulah orang kafir.” (A.S. dan Benedanto, 2001).

(不信伊斯兰教的人就是无信仰)

以上张振文的《黄西的故事》和《小妾素密拉的故事》都讲述了种族交流、通婚与宗教信 仰的问题, 还有很多作品都讲述了社会通婚的悲剧。虽然两个民族的子女可以结婚, 但社会上 
都认为愿意通婚的妇女的地位比一般妇女的地位还要低。尤其是他们的孩子们, 一般都是被社 会歧视的。

\section{4. 传统思想与新思想的冲突}

有些作品表现出传统思想与新思想的冲突，传统思想的代表是老一代的华侨，而新思想的 代表是年轻的一代的华侨子女，他们受到西方教育、模仿西方人生活的习惯。如：郭德怀 1930 年写的《元宵节》。文章利用幽默的手段写出当时印尼华侨看元宵的情况。文章的女主角丽叶刚 与多玛结婚, 丽叶的家族是个传统家族: 认为女人不可以和男人在街上行走。虽然他们已经结 婚了, 但是贤惠的妇女不应该表现出她的感情。他们也不可以在大众的面前手牵手; 而多玛的 家族是受到西方教育的家族, 结婚后他们不同背景的夫妻为了看元宵发生了冲突, 因为多玛想 带他妻子去和他朋友们一起吃元宵、去街上凑凑热闹, 而丽叶家庭认为那是没教养妇女或妓女 的行为。多玛很生气, 打算给丽叶家族一些教训, 通过朋友的劝告他故意跟一个男扮女装的朋 友在丽叶家人面前行走, 丽叶家人一看到他们的女儿嫁到一个不正当的丈夫就觉得很生气。丽 叶的堂妹看到多玛跟一个女人手拉手也很生气, 劝丽叶对多玛报仇, 让她跟一个女扮男装的他 在路上手拉手给多玛看, 可是结果被丽叶婆婆家发现, 两个家族发生了一个巨大的冲突, 最后 通过两个家族认识的一位伯伯解释事情的过程并告诉女方家庭现在是男女已经平等的时代, 应 该排除过去没有道理的传统观念。作家通过文章所发生的各个细节来讽刺那些还抱住不实际的 传统思想。作家希望通过作品可以让人民反省、认真地思考男女平、传统和现代思想的问题, 指导人们把错误的旧思想改变过来。

\section{5. 爱国主义精神}

郭德怀的小说《伯根地谷的悲剧》提到当时政治事件, 就是 1926 年在印尼爆发了共产党运 动, 后来被打平了。小说除了写努拉尼和莫答礼的爱情故事, 也将了一些革命的运动、爱国的 思想、对未来的国家前途的希望。像大部分华侨马来由文学作品的基本构思, 努拉尼和莫答礼 的爱情也经过了歪歪曲曲甚至需要经历了生和死才能走在一块儿, 结为夫妻, 但是命运好像在 玩弄他们, 刚过着两年的幸福日子, 努拉尼去世了。她把她的最好朋友一一苏巴亚交给苏巴亚。 苏巴亚的性格是作家盼望未来印尼子孙该拥有性格：聪明、能干、勇敢、忠心耿耿、慷慨、不 顾自己的利益去帮助别人、一直维持正义。作家也通过讲述巴布亚来写出他对国家的想法和盼 望。他盼望拥有一个自由、发达与茂盛的国家、也盼望很多种族和国家融洽地生活在一起、互 相尊重、没有互相压迫。这个作品真是个伟大的作品, 作家通过作品来推动读者战斗, 追求得 到真正自由的国家。郭德华的这部小说不但写得漂亮、而且含有独特的创新, 把 1926 年印尼发 生的革命跟人与人之间常发生的爱情、嫉恨、友情、贪婪、领导的腐败和为了达到某种目的而 不择手段的行为混合成为一个很有魅力的故事，代表了当时印尼华侨献上他对国家的爱心、献 上他的精神和思想，自持印尼独立。

\section{6. 娱乐性内容}

印尼侨生马来由文学产生的时期是部分人民刚从“文盲”摆脱出来的时期, 因此人们比较喜 欢阅读娱乐性较强的作品, 如: 取于日常生活作题材的爱情故事、笑话、武侠、等类作品。

印尼侨生马来由文学作品代表了印尼华人对印尼社会取了很大的贡献。除了文学上的贡献, 文学作品的发展也推动了出版事业的发展、活跃了印尼社会的文化生活、推动了印尼文化与中 国文化和西方文化的交流、推广及普及了通俗马来由语的社会上的用处, 为以后发展的印尼语 打下了基础，丰富了印尼语的词汇。 


\section{结语}

印尼侨生马来由文学是印尼现代文学的先驱。它拥有百年的历史、庞大的数量、多样化内 容的特征, 代表了印尼侨生对社会做出了巨大贡献。要研究印尼文学的发展如没有研究印尼侨 生马来由文学是不全面的。要研究印尼侨生马来由文学除了要先研究华侨社会和历史, 也要研 究当时的经济、政治和社会的文化。

\section{参考文献:}

李学民、黄昆章：《印尼华侨史》，广东高等教育出版社，2005 年

胡风：《文学与生活 密云期风习小记》，北京人民文学出版社，2001 年

耶谷。蘇玛尔卓、林万里：《印尼侨生马来由文学研究》, 香港获益出版事业有限公司, 1998 年

A.S, Markus dan Pax Benedanto. 2000. Kesastraan Melayu Tionghoa dan Kebangsaan Indonesia I. Jakarta: KPG.

Pax. 2001. Kesastraan Melayu Tionghoa dan Kebangsaan Indonesia II. Jakarta: KPG. 2001. Kesastraan Melayu Tionghoa dan Kebangsaan Indonesia III. Jakarta: KPG. 2001. Kesastraan Melayu Tionghoa dan Kebangsaan Indonesia IV. Jakarta: KPG. 2002. Kesastraan Melayu Tionghoa dan Kebangsaan Indonesia V. Jakarta: KPG. 2002. Kesastraan Melayu Tionghoa dan Kebangsaan Indonesia VI. Jakarta: KPG.

A.S, Markus. 2003. Kesastraan Melayu Tionghoa dan Kebangsaan Indonesia VII. Jakarta: KPG.

A.S., Markus dan Yul Hamiyati. 2002. Kesastraan Melayu Tionghoa dan Kebangsaan Indonesia VIII. Jakarta: KPG.

Nio Joe Lan.1962. Sastra Indonesia-Tionghoa. Jakarta: Gunung Agung.

Salmon, Claudine. 1985. Literature in Malay by the Chinese of Indonesia. Jakarta: Balai Pustaka.

Suaka, I Nyoman. 2004. “Latar Indonesia dalam Karya Sastra Tionghoa,” Bali Post eds. Januari 24. 